\title{
Anatomia e análise de óleo essencial das folhas de Hennecartia omphalandra J. Poisson (Monimiaceae)
}

\author{
Carlos A. Marques, ${ }^{*, 1,2}$ Gilda G. Leitão, ${ }^{3}$ Humberto R. Bizzo, ${ }^{4}$ Ariane L. Peixoto, ${ }^{5}$ \\ Ricardo C. Vieira ${ }^{1}$
}

${ }^{1}$ Laboratório de Morfologia Vegetal, Departamento de Botânica, Universidade Federal do Rio de Janeiro, Av. Brigadeiro Trompowsky, s/n, Ilha do Fundão, 21941-590 Rio de Janeiro-RJ, Brasil,

2, *Centro Federal de Educação Tecnológica de Química de Nilópolis, R. Lúcio Tavares, 1045, Centro, 26530-060

Nilópolis-RJ, Brasil,

${ }^{3}$ Núcleo de Pesquisas de Produtos Naturais, Universidade Federal do Rio de Janeiro, Av. Brigadeiro Trompowsky, s/n, Ilha do Fundão, 21941-590, Rio de Janeiro-RJ, Brasil,

${ }^{4}$ EMBRAPA, Agroindústria de Alimentos, Av. das Américas, 29501, Guaratiba, 23020-470

Rio de Janeiro-RJ, Brasil,

${ }_{5}^{5}$ Instituto de Pesquisas Jardim Botânico do Rio de Janeiro, Rua Jardim Botânico, 1008, Jardim Botânico, 22460-

070 Rio de Janeiro-RJ, Brasil

\begin{abstract}
RESUMO: Descreve-se a morfo-anatomia e a análise de óleo essencial das folhas de Hennecartia omphalandra J. Poisson (Monimiaceae), uma planta tóxica. A ocorrência de tricomas unicelulares, estômatos paracíticos; braquiesclereídes em grupos no pecíolo e na lâmina foliar, além de esclereídes vermiformes e ramiformes; sistema vascular em arco, com extremidades voltadas para o centro no pecíolo e na forma de arco atenuado na lâmina foliar, sendo o padrão de venação uma variação do tipo craspedódromo-semicraspedódromo, além de óleo essencial armazenado em idioblastos oleíferos não especializados no mesofilo, foram considerados caracteres importantes que podem auxiliar na sua morfo-diagnose. A análise do óleo essencial das folhas revelou a presença de monoterpenos, sesquiterpenos e álcoois sesquiterpênicos, sendo este o grupo mais significativo. Os componentes majoritários identificados foram $\beta$-felandreno $(24,0 \%)$, seguido por germacreno D $(10,5 \%)$, sabineno $(9,3 \%)$, biciclogermacreno $(8,4 \%)$ e $\beta$-elemeno $(5,3 \%)$.
\end{abstract}

Unitermos: Hennecartia omphalandra, Monimiaceae, plantas tóxicas, anatomia foliar, óleo essencial.

\begin{abstract}
Anatomy and essential oil analysis of the leaves from Hennecartia omphalandra J. Poisson (Monimiaceae)". This paper describes the morphological and anatomical aspects and the essential oil analysis of the leaves from Hennecartia omphalandra J. Poisson (Monimiaceae), a toxic plant. The presence of trichomes formed by a single cell, paracitic stomata, groups of braquisclereids in the petiole and leaf blade; vermiform and ramiform sclereids, vascular system in arc softly invaginated at ends in the petiole, and in a flat arc in the middle vein, being the venation pattern a variation of craspedodromous-semicraspedodromous type, and essential oil stored in oil idioblasts in the mesophyll were the most important characters that can help the morphological diagnosis. The analysis of essential oil of the leaves showed the presence of monoterpenes, as well as sesquiterpenes hydrocarbons and alcohols, being the latter the most significant group. The major identified compounds were $\beta$-phelandrene $(24.0 \%)$, germacrene D (10.5\%), sabinene $(9.3 \%)$, bicyclogermacrene $(8.4 \%)$ and $\beta$-elemene $(5.3 \%)$.
\end{abstract}

Keywords: Hennecartia omphalandra, Monimiaceae, toxic plants, leaf anatomy, essential oil.

\section{INTRODUÇÃO}

Desde épocas remotas as plantas tóxicas exercem um papel importante, seja através do uso como veneno de flechas ou como recurso em envenenamentos intencionais com fins políticos, militares ou pessoais (Schenkel et al., 2002). O estudo dessas plantas vem ganhando importância, pois, além de esclarecer diferentes aspectos relativos aos casos de intoxicações e de identificar constituintes químicos capazes de exercer ação tóxica, pode ainda fornecer substâncias ativas para o desenvolvimento de fármacos e inseticidas (Vieira et al., 2002; Amaral et al., 2006; Barbosa-Filho et al., 2007; Saúde-Guimarães \& Faria, 2007; Barbosa-Filho et al., 2008a; Corrêa et al., 2008; Sousa et al., 2008).

Neste contexto, a anatomia vegetal constituise em um instrumento eficaz, pois, além do aspecto descritivo, também contribui através dos dados 
fornecidos pelo estudo de estruturas secretoras, possibilitando elucidar aspectos relativos ao armazenamento e secreção de metabólitos secundários. Contudo, os estudos sobre anatomia de plantas tóxicas ainda são escassos. Mencionam-se os trabalhos de Panizza et al. (1982), sobre os elementos histológicos mais importantes para o diagnóstico de Cannabis sativa L. (Cannabinaceae); de Milanez \& Monteiro-Neto (1956) sobre os laticíferos de Euphorbia pulcherrima Willd. (Euphorbiaceae) e de Dieffenbachia picta Schott (Araceae), onde o estudo das células secretoras foi determinante no esclarecimento do seu mecanismo de ação (Carneiro et al., 1989; Ferreira et al., 2006).

Em espécies de Monimiaceae os estudos anatômicos também são restritos e privilegiam a descrição dos órgãos vegetativos aéreos (Metcalfe, 1987; Callado et al., 1997; Fischer et al., 1998; Palma et al., 2002; Callado et al., 2006). No Brasil, a descrição da morfologia externa e interna de espécies vegetais que servem como base para o desenvolvimento de fármacos, é determinada pela RDC ${ }^{\circ} 48$ da Anvisa, de 16/03/2004 (Anvisa, 2005).

Espécies pertencentes às famílias Monimiaceae ou de famílias próximas como Siparunaceae, são citadas pelo seu uso em medicina popular, como Siparuna apiosyce (Mart. ex Tul.) A.DC., utilizada no tratamento de distúrbios gastrointestinais, febres, gripes e outras afecções. Mollinedia brasiliensis Schott ex Tul. é considerada um forte antiespasmódico (Leitão et al., 1999) e em Siparuna pauciflora (Beurl.) A. DC. foi verificada atividade contra Plasmodium falciparum (Jenett-Siems et al., 2003). Estudos fitoquímicos têm destacado a presença de uma grande variedade de constituintes químicos, justificando o uso dessas espécies na medicina popular. Peumus boldus Molina é a espécie mais conhecida, sendo mencionada em diversas farmacopéias pelo seu uso contra dispepsias, náuseas e constipação intestinal (Brandão et al., 2006; Agra et al., 2007; Ruiz et al., 2008). Nessa espécie, encontram-se alcalóides benzilisoquinolínicos como boldina, isocordina e $N$-metillaurotetanina (Pietta et al., 1988). Não obstante, Hennecartia omphalandra J. Poisson. (Monimiaceae), popularmente conhecida como "canemeira", "pimenteira-do-mato" ou "arreganha" é considerada uma espécie tóxica, segundo o Centro de Investigações Toxicológicas/ SC, por ter causado grave intoxicação em crianças na cidade de Cândido de Abreu, PR, após a ingestão de sementes, segundo Schenkel et al. (2002). Este fato motivou o estudo morfológico e anatômico dos frutos (Marques, 2007; Marques et al., 2008) e das folhas de H. omphalandra J. Poisson., a fim de fornecer dados para a sua morfo-diagnose; além da análise do óleo essencial, como parte integrante do estudo fitoquímico e de atividade biológica, ainda em desenvolvimento.

\section{MATERIAL E MÉTODOS}

Estudo morfo-anatômico - Foram coletadas folhas de três espécimes ocorrentes na Chácara Recanto Beija-Flor, uma propriedade particular localizada no bairro Aviação Velha em Londrina, PR que apresenta latitude entre $23^{\circ} 08^{\prime} 47^{\prime \prime}$ e $23^{\circ} 55^{\prime} 46^{\prime \prime}$ S e longitude $50^{\circ} 52^{\prime} 23^{\prime \prime}$ e $51^{\circ} 19^{\prime} 11^{\prime \prime} \mathrm{W}$. A altitude média da cidade é de $576 \mathrm{~m}$ e o clima é subtropical, sendo a temperatura média anual de $21,4{ }^{\circ} \mathrm{C}$ (Nimer, 1989). A propriedade contém um fragmento remanescente de mata úmida, onde os três indivíduos femininos, coletados para este estudo, compõem o sub-bosque. Após coleta e identificação, o material botânico foi depositado e registrado no Herbário do Departamento de Botânica da Universidade Federal do Rio de Janeiro (RFA), sob o número 30.840. Para análise anatômica foram coletadas somente folhas completamente expandidas do $4^{\circ}$ ao $6^{\circ}$ nós, localizadas nos ramos mais basais. Foram posteriormente processadas amostras da região mediana da lâmina foliar e o pecíolo foi fragmentado nas regiões proximal, mediana e distal.

As amostras, após coleta e processamento, foram fixadas em FPA $50 \%$ e os fragmentos emblocados em Historesina Leica, segundo recomendações do fabricante, sendo posteriormente seccionados transversalmente ao micrótomo rotativo com espessura de 6-10 $\mu \mathrm{m}$. A coloração dos cortes foi feita utilizandose Azul de toluidina $0,05 \%$, sendo montados em lâminas permanentes (Ruzin, 1999). Os testes histoquímicos foram feitos em cortes de material recém-coletado, utilizando-se Floroglucina para identificação de lignina; Lugol para identificar amido e Sudan IV para substâncias lipofílicas (Johansen, 1940). Para a deteç̧ão de taninos, foi utilizada a mistura ácido acético glacial/ formaldeído/ $\mathrm{FeSO}_{4}$ (Ruzin, 1999) Os cristais foram reconhecidos pelo teste de solubilidade em ácido clorídrico $10 \%$ e insolubilidade em ácido acético $10 \%$ e, para a dissociação da folha, foi utilizada a mistura de Jeffrey por 48-72 horas - solução aquosa de Ácido nítrico $10 \%$ e solução aquosa de Àcido crômico $10 \%$, na proporção 1:1 (Johansen, 1940). As observações relativas à morfologia externa foram feitas ao microscópio estereoscópico Nikon SMZ 800. As fotomicrografias foram obtidas ao Fotomicroscópio III da Zeiss e os esquemas foram feitos ao microscópio Zeiss Axiolab equipado com câmara clara. Para determinação do tipo de estômato, seguiu-se a nomenclatura proposta por Wilkinson (1979) e para determinação do padrão de venação seguiu-se Hickey (1979).

Extração e análise do óleo essencial - A coleta de folhas para extração do óleo essencial foi realizada no verão (23/02/2006), numa época onde nenhum indivíduo apresentou floração nem frutificação, tendo sido usados $150 \mathrm{~g}$ de folhas frescas sem sintomas de necrose, clorose ou contaminação por fungos. As folhas foram fragmentadas e submetidas à hidrodestilação 
em um aparelho do tipo Clevenger por 1 hora e 30 minutos, de onde se obteve $0,1 \mathrm{~mL}$ de óleo. O óleo essencial de $H$. omphalandra J. Poisson foi analisado no dia subseqüente por cromatografia gasosa $(\mathrm{CG}) \mathrm{em}$ um equipamento Agilent HP 5890, série II, equipado com um detector de ionização de chama, mantido a $280{ }^{\circ} \mathrm{C}$ e uma coluna capilar Ultra $2(25 \mathrm{~m} \mathrm{x} 0,20$ $\mathrm{mm} \times 0,33 \mu \mathrm{m})$, utilizando hidrogênio $\left(1,0 \mathrm{~mL} \cdot \mathrm{min}^{-1}\right)$ como gás carreador. A programação de temperatura do forno foi de 60 a $240{ }^{\circ} \mathrm{C}$, com incremento de 3 ${ }^{\circ} \mathrm{C} \min ^{-1}$. A amostra, $1,0 \mu \mathrm{L}$ de uma solução a $1 \%$ do óleo eseencial em hexano, foi injetada no modo com divisão de fluxo $(1: 100)$ em injetor mantido a $250^{\circ} \mathrm{C}$. A quantificação foi realizada por normalização de área. A análise por espectrometria de massas foi realizada em sistema Agilent 5973N, acoplado a um cromatógrafo à gás Agilent 6890, equipado com uma coluna capilar HP5MS $(30 \mathrm{~m} \times 0,25 \mathrm{~mm} \times 0,25 \mu \mathrm{m})$, utilizando hélio como gás carreador a 1,0 mL. $\mathrm{min}^{-1}$. $\mathrm{O}$ detector de massas foi operado no modo impacto de elétrons com energia de $70 \mathrm{eV}$. Os demais parâmetros de operação foram os mesmos acima. Os espectros de massas foram comparados com aqueles da biblioteca do espectrômetro (Wiley 6th ed.) e com espectros disponíveis na literatura (MacLafferty \& Stanffer, 1989; Adams, 1995; 2001). Para a identificação também foi calculado o índice de Kovats, utilizando-se os dados de uma série homóloga de hidrocarbonetos alifáticos saturados $\left(\mathrm{C}_{7}\right.$ a $\left.\mathrm{C}_{26}\right)$ na mesma coluna e condições da análise de $\mathrm{CG}$ do óleo. Os índices de Kovats calculados foram comparados com índices da literatura (Adams, 1995; 2001) e a identificação dos componentes do óleo foi efetuada com dados de espectrometria de massas e do índice de Kovats.

\section{RESULTADOS E DISCUSSÃO}

A folha apresenta pecíolo curto, lâmina foliar simétrica, de consistência membranácea, com ápice cuspidado, base aguda e margem dentada, com nervuras reticuladas, proeminentes na face abaxial (Fig. 1).

$O$ padrão de venação apresenta uma variação do tipo craspedódromo-semicraspedódromo, onde uma das ramificações de cada nervura secundária prolonga-se em direção à margem, formando uma área pontiaguda, dando o aspecto cassidato ao bordo foliar. A outra ramificação vai se anastomosar com a ramificação proveniente da outra nervura secundária. Dessa maneira, formam-se grandes aréolas reticuladas e ortogonais (Fig. 1) com nervuras que vão se ramificando (Fig. 2) até a $7^{\mathrm{a}}$ ordem, sendo as terminações vasculares livres, simples ou ramificadas, margeadas por células parenquimáticas que contém pequenos cristais cúbicos ou romboédricos em grande quantidade (Fig. 3).

A diferença observada em relação ao padrão semicraspedódromo típico é que, por vezes, as nervuras terciárias também se anastomosam e, nesse caso, são os prolongamentos das nervuras terciárias que se estendem para formar as terminações vasculares (Fig. 1). Hickey (1979) menciona a família Monimiaceae como exemplo de folhas com terminações marginais cassidatas. $H$. omphalandra segue, portanto, o padrão encontrado em outros gêneros da família.

A venação marginal se forma pela anastomose das nervuras de menor calibre, de onde partem terminações livres, simples ou ramificadas, caracterizando como "incompleta" a venação marginal nas regiões de contorno regular, compreendidas como as áreas entre 2 terminações pontiagudas (Fig. 2). Estas áreas pontiagudas são formadas pelo prolongamento de uma nervura secundária ou terciária, o que confere rigidez a essa região (Fig. 4). Contudo, Peixoto (1976), ao descrever a morfologia externa de $H$. omphalandra, classificou o padrão de venação foliar como broquidódromo. Posteriormente, Peixoto (1979) descreveu, em Mollinedia, padrão de venação broquidódromo, mas quando a margem é dentada, o padrão assemelha-se ao padrão semicraspedódromo, onde as nervuras terciárias formam arcos próximos aos bordos, às vezes unindo duas nervuras secundárias.

Segundo Rury \& Dickson (1977), o padrão de venação craspedódromo aparece, em diversas espécies, como resultado da modificação ontogenética do padrão broquidódromo e Lorence (1985) encontrou essa transição entre os padrões broquidódromo e craspedódromo em Ephippiandra madagascarensis (Cav.) Lorence.

Optou-se por manter a definição do padrão de venação de $H$. omphalandra como uma variação do tipo craspedódromo-semicraspedódromo, baseandose nas definições de Hickey (1979), para os espécimes coletados em Londrina-PR. Maiores detalhes acerca das definições dos padrões, bem como a comparação com o material estudado podem ser encontrados em Marques (2007).

O pecíolo nos 3 indivíduos estudados apresentou contorno plano ou levemente côncavo na face adaxial e convexo na face abaxial (Fig. 5). A epiderme é unisseriada, com paredes retas em corte transversal e cutícula delgada que reage positivamente ao Sudan IV. Observaram-se também alguns raros tricomas tectores unicelulares. Subjacente à epiderme na face adaxial, ocorre um colênquima discreto constituído por 1-3 estratos, sendo seguido pelo parênquima fundamental. Em meio a essas células parenquimáticas, ocorrem braquiesclereides em grupos, dispersas aleatoriamente (Fig. 5, 6 e 7). Da mesma forma, foi possível notar que algumas células parenquimáticas armazenam conteúdo que reage positivamente ao Sudan IV, o que os caracteriza como idioblastos oleíferos (Fig. 6). Outras células parenquimáticas armazenam cristais romboédricos, cúbicos ou estilóides de pequenas dimensões (Fig. 6).

O sistema vascular possui forma de arco, com extremidades levemente voltadas para o centro, 
circundado por células parenquimáticas em grupos, formando uma bainha (Fig. 5 e 7). Na porção distal as mesmas características são mantidas, à exceção da presença de fibras perivasculares que envolvem as células parenquimáticas e que, por sua vez, envolvem o feixe vascular.

Muitas vezes o pecíolo apresenta caracteres diagnósticos. Esses dados não devem ser desprezados na análise anatômica, já que a lâmina foliar e o pecíolo são muitas vezes macerados, moídos ou pulverizados juntos, principalmente em espécies em que o pecíolo é curto, como Peumus boldus. Palma et al. (2002) não descreveram anatomicamente o pecíolo em $P$. boldus. Por outro lado, em Siparuna apiosyce, caracteres ocorrentes no pecíolo e na lâmina foliar como tricomas tectores, cristais aciculares e células oleíferas foram usados no reconhecimento da droga (Fischer et al., 1998). Portanto, a utilização de características do pecíolo observadas em $H$. omphalandra, como a conformação do sistema vascular, os tipos de cristais e a presença de idioblastos oleíferos, como caracteres diagnósticos, são válidas.

Em H.omphalandra a lâmina foliar é hipostomática e os estômatos são paracíticos (Fig. 8), sendo possível observar a ocorrência de estômatos contíguos (Fig. 8). Diferentes autores afirmam que em Monimiaceae os estômatos são paracíticos ou anomocíticos (Solereder, 1908; Money et al., 1950; Metcalfe, 1987). H. omphalandra segue o padrão referido para a família, tendo-se observado somente estômatos paracíticos.

A epiderme é formada por células poliédricas de tamanho muito reduzido (Fig. 9 e 11), paredes anticlinais retas, por vezes levemente curvas (Fig. 8) com tricomas tectores eretos e unicelulares (Fig. 8), observados em ambas as faces, inclusive sobre as nervuras, raramente visualizados na epiderme adaxial. Estes tricomas, quando caem, deixam cicatriz. Segundo Solereder (1908) e Metcalfe (1987), em Monimiaceae (incluindo Siparuna), os tricomas são exclusivamente tectores, a maioria unicelulares, estando presentes em todos os gêneros, à exceção de Macropeplus, Macrotorus, Schrameckia e Xymalos. Tendem a estar dispostos em tufos em Daphnandra, Doryphora e Laurelia, em longos tufos com base esclerificada em Peumus e Siparuna, unicelulares bifurcados em Atherospermum, Matthaea e Mollinedia e peltados em Monimia, Hortonia e Palmeria.

A forma dos tricomas, bem como o tipo de estômato foram considerados caracteres diagnósticos que facilitaram o reconhecimento de folhas pulverizadas de Siparuna apiosyce (Mart.) A. DC. (Siparunaceae) e do extrato fluido ou seco por compressão direta de Peumus boldus Molina (Fischer et al., 1998; Palma et al., 2002).

O mesofilo apresentou 1-2 estratos subepidérmicos na face adaxial, sendo o segundo estrato descontínuo e apenas 1 estrato por vezes observado na face abaxial. Essas células possuem grandes dimensões (Fig. 9). Segundo Money et al. (1950), a hipoderme está presente na maioria dos gêneros de Monimiaceae. H. omphalandra, por apresentar esses estratos, caracterizados como hipoderme por esses autores, segue o padrão referido para a maioria dos gêneros da família.

A lâmina foliar é dorsiventral (Fig. 9 e 10). O parênquima paliçádico ocorre em 1 estrato, seguido por um estrato de transição e pelo parênquima lacunoso em 8-10 camadas, com lacunas de consideráveis dimensões (Fig. 9). No parênquima lacunoso, algumas células reagem positivamente ao Sudan IV (Fig. 9 e 10). Ou seja, o conteúdo é armazenado no vacúolo de células ordinárias do parênquima lacunoso que constituem idioblastos oleíferos. Tal fato já não é observado no fruto (Marques et al., 2007), onde o conteúdo fica armazenado em células secretoras especializadas no mesocarpo. Tanto nas folhas quanto nos frutos extraiuse óleo essencial.

Famílias basais de angiospermas, como Monimiaceae e Lauraceae são conhecidas pela presença de células oleíferas em órgãos vegetativos (Gottlieb \& Salatino, 1987). Em S. apiosyce (Siparunaceae), são descritas células oleíferas no mesofilo e no caule (Fischer et al., 1998) e em Peumus boldus, foram observadas células oleíferas em meio ao parênquima lacunoso (Palma et al., 2002). Money et al. (1950) citam a ocorrência de células oleíferas na folha em muitos gêneros de Monimiaceae e mencionam a ausência dessas células em Macropeplus.

Em todas as regiões do mesofilo, à exceção dos elementos vasculares, também foi observada a presença de uma grande quantidade de pequenos cristais cúbicos e romboédricos, de tamanho reduzido, sendo que nas nervuras secundárias e nas de menor calibre, a bainha de células parenquimáticas que as envolvem contém grande quantidade desses cristais (Fig. 10). Segundo Solereder (1908), esses cristais são típicos da família Monimiaceae e recentemente foram considerados um caráter diagnóstico em Peumus boldus por Palma et al. (2002). Já S. apiosyce possui cristais aciculares (Fischer et al., 1998). Apesar de possuir cristais com tamanho e formas típicos da família, sua presença abundante em toda a lâmina foliar, especialmente na bainha em torno do feixe, também pode auxiliar no reconhecimento de Hennecartia.

Além da bainha de células parenquimáticas repletas de cristais, foram encontradas esclereídes e fibras acompanhando as nervuras. No material macerado, identificou-se esclereídes que foram reunidas em grupos distintos (Fig. 13 e 14). Segundo Rao \& Bhupal (1973), esclereídes como as da Fig. 13 podem ser classificadas como "vermiformes curtos". Segundo estes autores tratam-se de variações de macroesclereídes. Já as esclereídes da Fig. 14 são definidas como "ramiformes". Segundo esses autores, esse tipo de esclereíde pode possuir terminações ramificadas na forma de T, I ou Y (Fig. 14 a-c). 
$\mathrm{Na}$ região da nervura mediana observou-se sistema vascular na forma de arco atenuado, seguido por células parenquimáticas e, estas, por fibras perivasculares que podem formar um anel (Fig. 12). Voltado para a face adaxial, ocorrem ainda 2 pequenos feixes, localizados acima do feixe maior (Fig. 12). Subjacente à epiderme adaxial, ocorre um colênquima angular em 3-4 estratos que, na verdade, corresponde à continuidade da hipoderme, encontrada ao longo da lâmina foliar. Na região do parênquima fundamental, também ocorrem células parenquimáticas de conteúdo oleífero (Fig. 12). Money et al. (1950) afirmam que o padrão de vascularização do pecíolo e da lâmina foliar varia consideravelmente em muitos gêneros e espécies, às vezes em folhas que estão em lados diferentes da mesma planta. Em espécies de Monimia, Hortonia e Palmeria, o sistema vascular pode se fechar em um cilindro pela concrescência das margens na face adaxial, mas em espécies de Matthaea e Steganthera, partes do arco atenuado podem se desprender na face adaxial, formando feixes menores, tal como foi observado em H. omphalandra.

O bordo foliar, nas áreas de contorno regular, é preenchido por 1 estrato de hipoderme. Subjacentes a este estrato ocorrem células parenquimáticas provenientes tanto do parênquima paliçádico quanto do lacunoso que, inclusive, podem armazenar conteúdo que reage ao Sudan IV, além de pequenos feixes vasculares (Fig. 11).

\section{Análise do óleo essencial}

A composição química do óleo essencial é mostrada na Tabela 1 . O óleo essencial de $H$. omphalandra é constituído por cerca de 35 constituintes químicos monoterpênicos e sesquiterpênicos, incluindo terpenos oxigenados. A identificação das substâncias presentes no óleo essencial foi feita através da comparação dos seus índices de Kovats calculados com os da literatura (Adams, 1995; 2001) e pela comparação de seus espectros de massas com os da literatura especializada (MacLafferty \& Stanffer, 1989). Dessa forma, identificou-se 31 constituintes químicos, correspondendo a $88,6 \%$ do total. A presença de 19 sesquiterpenos caracteriza este grupo como o mais significativo dentre as substâncias encontradas, sendo que 6 dos constituintes identificados são sesquiterpenos oxigenados: nerolidol, germacreno-D4-ol, óxido de cariofileno, epi- $\alpha$-muurolol, $\alpha$-muurolol e $\alpha$-cadinol (Tabela 1). Com isso, a soma de todos os sesquiterpenos corresponde a $54,3 \%$ do total da composição do óleo essencial. Observou-se ainda a ocorrência de 16 monoterpenos, o que corresponde a $45,7 \%$ do total. O constituinte químico majoritário deste óleo é um monoterpeno, o $\beta$-felandreno $(24,0 \%)$, seguido por germacreno D $(10,5 \%)$, sabineno $(9,3 \%)$, biciclogermacreno $(8,4 \%)$ e $\beta$-elemeno $(5,3 \%)$ ) (Tabela $1)$.

$\mathrm{Na}$ região dos monoterpenos, a presença de $\beta$-felandreno como constituinte mais abundante no óleo essencial das folhas $(24,0 \%)$ merece destaque, devendo-se considerar ainda a presença de $\alpha$-felandreno $(2,0 \%)$ (Tabela 1). Quando somados, os teores de felandreno no óleo obtido das folhas alcançam $26 \%$. Tal fato chama atenção pelo fato de existirem referências que consideram indesejável a presença de teores de felandreno superiores a $5 \%$ pela ação cardíaca que provocam (Simões \& Spitzer, 2002). Portanto, a ocorrência dessa substância em altos teores nas folhas sugere que este fator que possa contribuir para a toxidez de H. omphalandra.

Em óleos essenciais onde a quantidade de sabineno é significativa, como em Clausena anisata (Willd.) J.D. Hook ex benth. (Rutaceae) (33.0\%), verificou-se atividade antimicrobiana (Gundidza et al., 1994). Na espécie estudada, sabineno (9,3\%) e germacreno $\mathrm{D}(10,5 \%)$ também ocorrem em proporções significativas.

Terpenos oxigenados como linalol $(1,2 \%)$ e terpin-4-ol $(1,1 \%)$ também foram encontrados entre os constituintes do óleo essencial das folhas. Em Peumus boldus Mol., esses álcoois terpênicos também compõem o óleo essencial das folhas (Jorge-Neto et al., 1989; Bruneton, 1991). O linalol também é o componente principal do óleo essencial de Aniba rosaeodora Ducke e Ocotea duckei Kosterm. (Lauraceae) (Gottlieb, 1972; Barbosa-Filho et al., 2008b) que alcança alto valor comercial pelo seu uso na indústria de perfumaria (Rizzini \& Mors, 1976). Contudo, na espécie estudada, esse constituinte químico não figura entre os

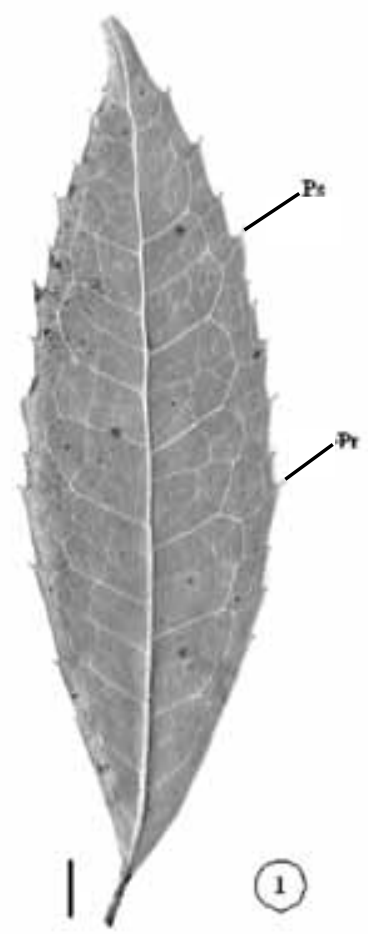

Figura 1. Face abaxial da folha mostrando o padrão de venação, onde se observam as terminações pontiagudas da margem, formadas pelos prolongamentos das nervuras secundárias $(\mathrm{Ps})$ e terciárias $(\mathrm{Pt})$. Barra $1 \mathrm{~cm}$. 
Tabela 1. Constituintes químicos presentes no óleo essencial das folhas de H. omphalandra.

IK - índice de Kovats; N.I.- não identificado; a - Adams (1995); b - Adams (2001); c - Mac Lafferty \& Stanffer (1989).

\begin{tabular}{|c|c|c|c|c|c|}
\hline Nome constituinte & $\begin{array}{l}\text { Tempo retenção } \\
\text { (min.) }\end{array}$ & Área (\%) & $\begin{array}{c}\text { IK } \\
\text { calculado }\end{array}$ & IK literatura & Referência utilizada \\
\hline N.I & 5,016 & 1,8 & 930 & - & - \\
\hline$\alpha$-pineno & 5,185 & 4,3 & 937 & 939 & $\mathrm{a}$ \\
\hline canfeno & 5,538 & 4,7 & 952 & 953 & $\mathrm{a}$ \\
\hline sabineno & 6,150 & 9,3 & 976 & 976 & $\mathrm{a}, \mathrm{b}$ \\
\hline$\beta$-pineno & 6,242 & 1,0 & 980 & 980 & $\mathrm{a}$ \\
\hline$\beta$-mirceno & 6,584 & 2,1 & 992 & 991 & a \\
\hline$\alpha$-felandreno & 6,990 & 2,0 & 1006 & 1005 & a \\
\hline$\delta$-3-careno & 7,172 & 2,3 & 1012 & 1011 & $\mathrm{a}$ \\
\hline$\alpha$-terpineno & 7,362 & 0,3 & 1018 & 1018 & a \\
\hline$p$-cimeno & 7,611 & 0,8 & 1025 & 1026 & $\mathrm{a}$ \\
\hline$\beta$-felandreno & 7,787 & 23,9 & 1033 & 1031 & a \\
\hline N.I. & 8,657 & 0,1 & 1059 & - & - \\
\hline$\gamma$-terpineno & 8,738 & 0,7 & 1062 & 1062 & $\mathrm{a}$ \\
\hline terpinoleno & 9,794 & 0,6 & 1090 & 1088 & $\mathrm{a}$ \\
\hline linalol & 10,207 & 1,2 & 1100 & 1098 & a \\
\hline terpin-4-ol & 13,285 & 1,1 & 1179 & 1177 & $\mathrm{a}$ \\
\hline N.I. & 22,264 & 0,3 & 1386 & - & - \\
\hline$\beta$-elemeno & 22,589 & 5,3 & 1393 & 1391 & a \\
\hline$E$-cariofileno & 23,703 & 2,8 & 1419 & 1418 & $\mathrm{a}, \mathrm{c}$ \\
\hline$\alpha$-humuleno & 25,136 & 0,6 & 1454 & 1454 & $\mathrm{a}$ \\
\hline$\gamma$-muuroleno & 26,169 & 0,7 & 1478 & 1477 & a \\
\hline germacreno D & 26,356 & 10,5 & 1482 & 1480 & a \\
\hline$\beta$-selineno & 26,528 & 0,5 & 1486 & 1485 & $\mathrm{a}, \mathrm{c}$ \\
\hline biciclogermacreno & 27,001 & 8,4 & 1496 & 1494 & a \\
\hline$\alpha$-muuroleno & 27,163 & 0,4 & 1500 & 1499 & $\mathrm{a}$ \\
\hline germacreno A & 27,342 & 4,0 & 1505 & 1503 & a \\
\hline$\gamma$-cadineno & 27,726 & 0,4 & 1515 & 1513 & a \\
\hline$\delta$-cadineno & 28,109 & 1,2 & 1525 & 1524 & a \\
\hline nerolidol & 29,772 & 0,7 & 1566 & 1564 & $\mathrm{a}$ \\
\hline germacreno-D-4-ol & 30,195 & 1,9 & 1576 & 1574 & $\mathrm{a}$ \\
\hline óxido de cariofileno & 30,474 & 2,0 & 1583 & 1581 & $\mathrm{a}$ \\
\hline N.I. & 30,692 & 0,7 & 1588 & - & - \\
\hline 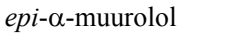 & 32,812 & 1,0 & 1643 & 1641 & $\mathrm{a}$ \\
\hline$\alpha$-muurolol & 32,987 & 0,2 & 1647 & 1645 & a \\
\hline$\alpha$-cadinol & 33,300 & 2,2 & 1655 & 1653 & $\mathrm{a}$ \\
\hline
\end{tabular}




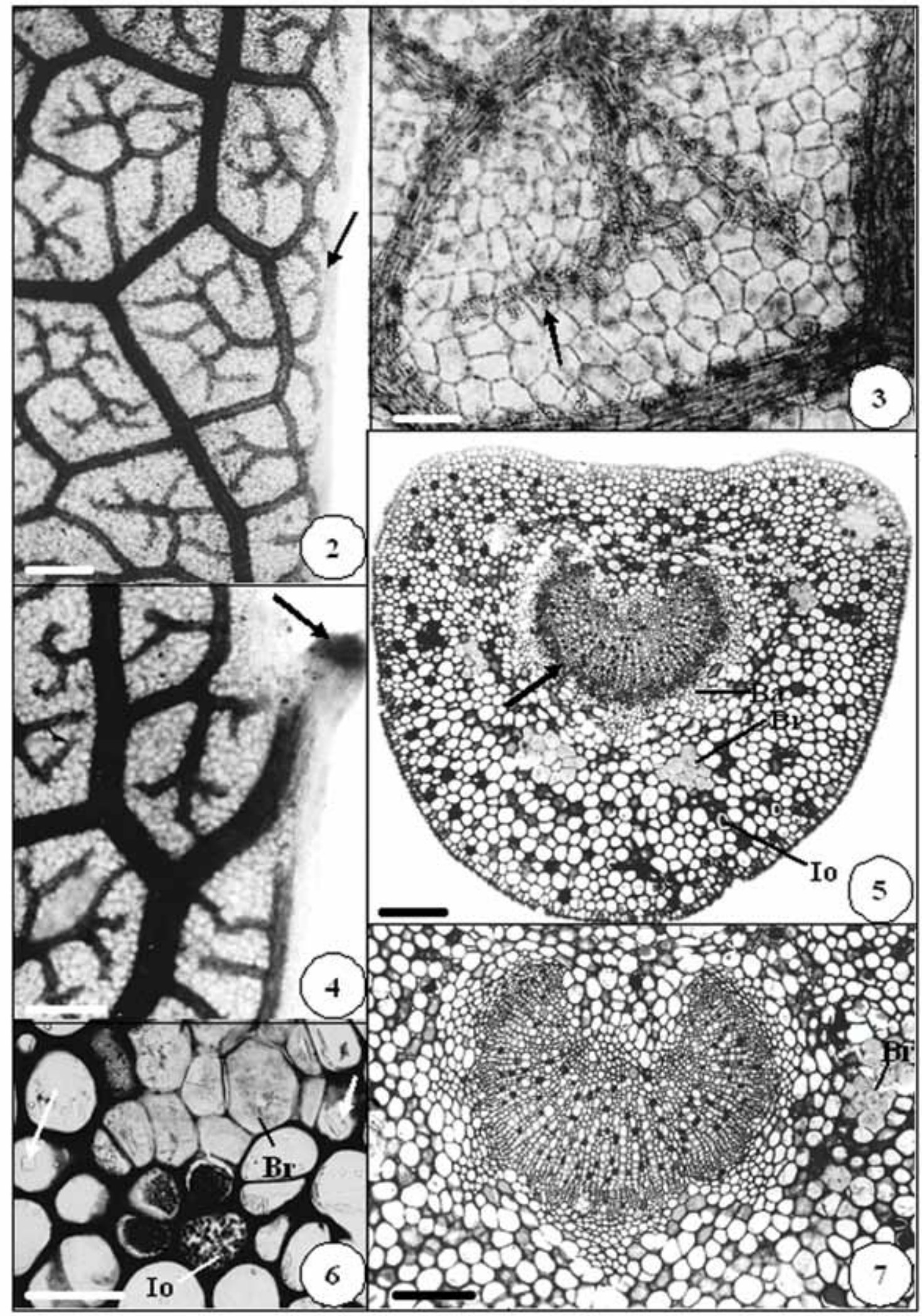

Figuras 2-7. 2. Venação marginal em detalhe $(\rightarrow)$. Barra $230 \mu \mathrm{m}$. 3. Detalhe dos cristais que acompanham as terminações vasculares. $(\rightarrow)$. Barra $30 \mu \mathrm{m}$. 4. Porção dentada da margem, preenchida pelo prolongamento de uma nervura secundária $(\rightarrow)$. Barra $50 \mu \mathrm{m}$. 5. Porção mediana do pecíolo, observando-se o sistema vascular em arco, com extremidades voltadas para o centro $(\rightarrow)$. Barra $250 \mu \mathrm{m}$. 6. Braquiesclereídes, idioblastos oleíferos e cristais $(\rightarrow)$ no pecíolo. Barra $50 \mu \mathrm{m}$. 7. Detalhe do sistema vascular em arco no pecíolo. Barra $100 \mu \mathrm{m}$. Io - idioblastos oleíferos; $\mathrm{Ba}$ - bainha de células parenquimáticas; $\mathrm{Br}$ braquiesclereídes. 


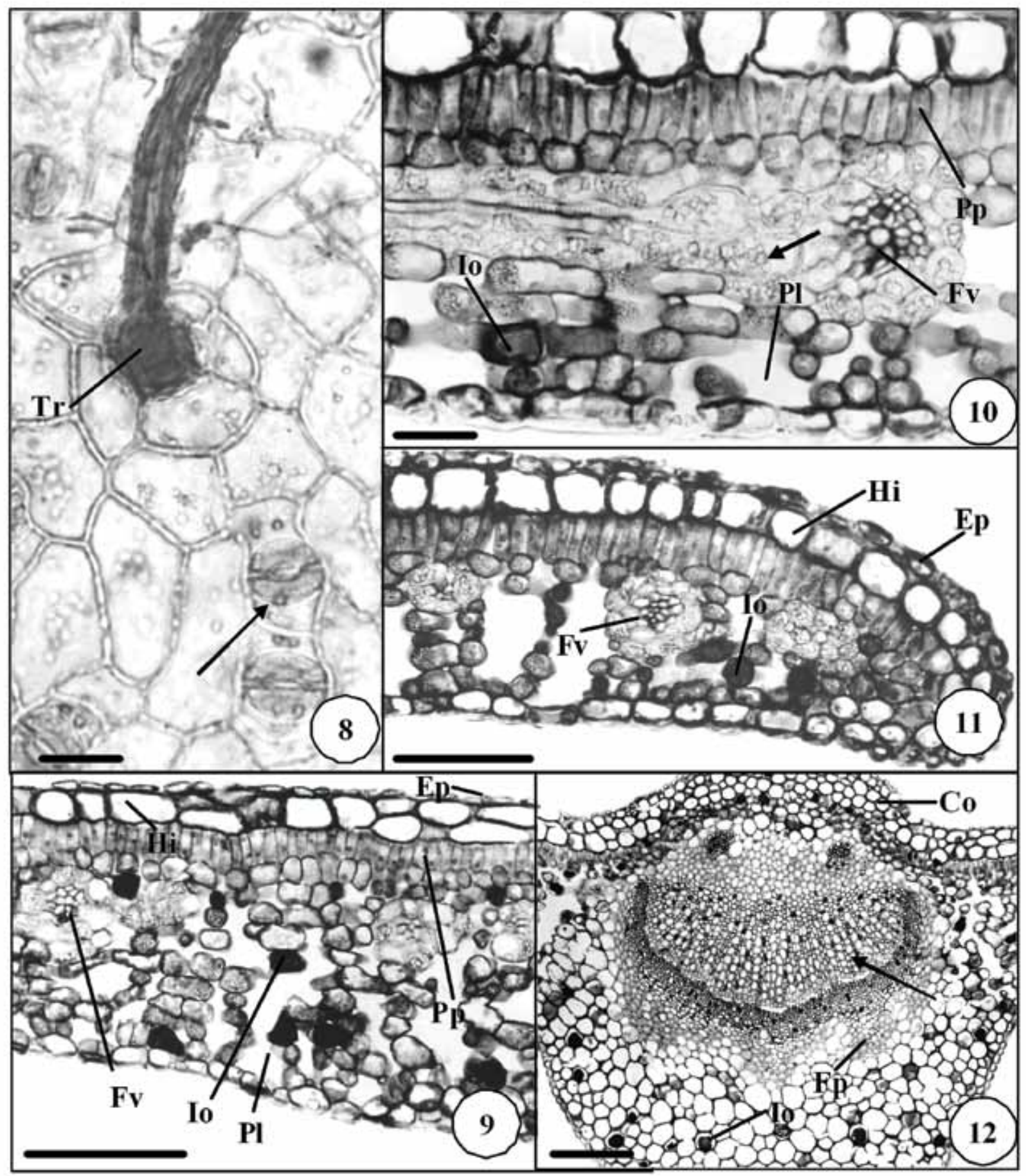

Figuras 8-12. 8. Epiderme abaxial em detalhe, mostrando o traçado reto das paredes, estômatos paracíticos $(\rightarrow)$ e tricomas tectores. Barra $25 \mu \mathrm{m}$. 9. Secção transversal da lâmina foliar, mostrando os diferentes estratos que compõem o mesofilo. Barra $100 \mu \mathrm{m}$. 10. Cristais $(\rightarrow)$ e idioblastos oleíferos, respectivamente, na bainha que envolve um feixe vascular e no parênquima lacunoso. Barra $25 \mu \mathrm{m}$. 11. Bordo foliar em detalhe. Barra $65 \mu \mathrm{m}$. 12. Secção transversal, no nível da nervura mediana, onde se observa sistema vascular em arco atenuado $(\rightarrow)$, circundado por fibras perivasculares. Barra $250 \mu \mathrm{m}$. Tr - tricoma tector, Ep epiderme, Hi - hipoderme, Pp - parênquima paliçádico, Pl - parênquima lacunoso, Fv - feixe vascular, Io - idioblastos oleíferos, Fp - fibras perivasculares, Co - Colênquima. 

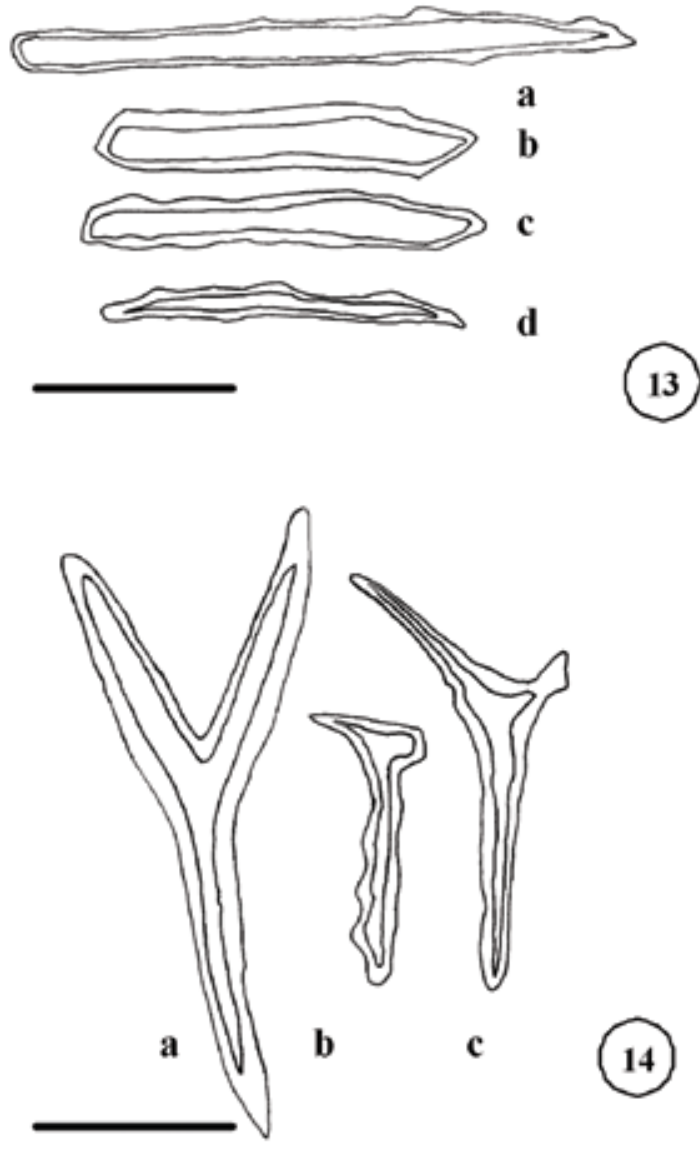

Figuras 13 e 14. Tipos de esclereídes encontradas nas folhas. 13 a-d. Esclereídes vermiformes curtos. 14 a-c. Esclereídes ramiformes. Barra $30 \mu \mathrm{m}$.

majoritários. O óxido de cariofileno $(2,0 \%)$, presente somente nas folhas de $H$. omphalandra, também foi encontrado em Mollinedia gilgiana, M. schottiana, M. glaziovii, e M. salicifolia, sendo o constituinte principal do óleo essencial de M. glaziovii, e M. salicifolia (Moreira et al., 2001). Segundo Harborne (1991), a presença de derivados do cariofileno tem importância ecológica, pois são repelentes naturais contra formigascortadeiras, sendo o óxido de cariofileno mais efetivo. Tal fato explica sua ausência nos frutos e presença nas folhas da espécie estudada.

A presença de sesquiterpenos, como constituintes majoritários do óleo essencial, pode ser observada, não só na espécie estudada, mas em espécies dos gêneros Mollinedia, bem como em famílias próximas como Siparunaceae e Lauraceae, onde sesquiterpenos interrelacionados ao eudesmano e germacrano foram localizados nos gêneros Lindera e Neolitsea (Lauraceae) (Gottlieb, 1972). Em Aristolochiaceae, o biciclogermacreno é o constituinte principal de espécies como Aristolochia argentina (Priestap et al., 2003). Cabe lembrar que o biciclogermacreno corresponde ao quarto constituinte mais abundante no óleo essencial obtido das folhas $(8,4 \%)$. Já o germacreno D é o segundo constituinte mais representativo $(10,5 \%)$.

Sesquiterpenos como o $\beta$-elemeno estão presentes em proporção significativa nas folhas. Em $H$. omphalandra, o $\beta$-elemeno $(5,0 \%)$ também pode ser encontrado em espécies como $S$. guianensis (Siparunaceae) (Antonio et al., 1984), Mollinedia gilgiana, M. schottiana, M. glaziovii, e M. salicifolia (Moreira et al., 2001). Em Aristolochia triangularis e A. rodriguesia (Aristolochiaceae),o $\beta$-elemeno também figura entre os constituintes majoritários do óleo essencial (Leitão et al., 1991). Já na família Lauraceae, faz-se menção à ocorrência desse sesquiterpeno na concentração de 1-5\% em Laurus nobilis (Hokwerda et al., 1982). A atividade anticancerígena do $\beta$-elemeno também tem sido bem estudada. Wu et al. (1999), Zou et al. (2001) e Wang et al. (2005) descreveram a atividade dessa substância contra células que formam diferentes tipos de câncer, como células leucêmicas e do "câncer de Lung", através da indução de apoptose nessas células tumorais.

Desta forma, a identificação de constituintes do óleo essencial nas folhas revela características que se assemelham a outros gêneros de Monimiaceae, bem como de famílias relacionadas à mesma ordem. Além disso, a presença de constituintes químicos mencionados pela sua atividade biológica desperta o interesse sobre a espécie estudada, no que diz respeito à realização de ensaios de atividade biológica.

Com base nos resultados obtidos, podese destacar como caracteres farmacognósticos mais relevantes:

A ocorrência de tricomas tectores unicelulares, estômatos paracíticos; braquiesclereídes em grupos no pecíolo e na lâmina foliar, além de esclereídes vermiformes e ramiformes; sistema vascular em arco, com extremidades voltadas para o centro no pecíolo e na forma de arco atenuado na lâmina foliar, sendo o padrão de venação uma variação do tipo craspedódromosemicraspedódromo, além de óleo essencial armazenado em idioblastos oleíferos do parênquima lacunoso.

A identificação do $\beta$-felandreno $(24,0 \%)$, seguido por germacreno D (10,5\%), sabineno $(9,3 \%)$, biciclogermacreno $(8,4 \%)$ e $\beta$-elemeno $(5,3 \%)$ como componentes majoritários, destacando-se que teores de felandrenos superiores a $5 \%$ são mencionados na literatura como indesejáveis pela sua ação tóxica.

\section{AGRADECIMENTOS}

À CAPES pela bolsa concedida e ao pesquisador Walter M. Kranz do Instituto Agronômico do Paraná pelo valioso auxílio na coleta e envio de material botânico.

\section{REFERÊNCIAS}


Adams RP 1995. Identification of essential oil components by gas chromatography/ mass spectroscopy. Carol Stream, Illinois: Allured Publishing Corporation.

Adams RP 2001. Identification of essential oil components by gas chromatography/ mass spectroscopy. $2^{\text {nd }}$ edition, Carol Stream, Illinois: Allured Publishing Corporation.

Agra MF, França PF, Barbosa-Filho JM 2007. Synopsis of the plants known as medicinal and poisonous in Northeast of Brazil. Rev Bras Farmacogn 17: 114140.

Amaral FMM, Ribeiro MNS, Barbosa-Filho JM, Reis AS, Nascimento FRF, Macedo RO 2006. Plants and chemical constituents with giardicidal activity. Rev Bras Farmacogn 16 (Supl.): 696-720.

Anvisa 2005. Agência Nacional de Vigilância Sanitária, RDC $n^{\circ} 48$ de 16/03/2004. In: http:/www.anvisa. gov.br, acessada em Novembro de 2005. Antonio TM, Waller GR, Mussinan CJ 1984. Monimiaceae. I. Composition of essencial oil from the leaves of Siparuna guianensis. Chem Ind (London) 14: 95-115.

Barbosa-Filho JM, Nascimento-Júnior FA, Tomaz ACA, Athayde-Filho PF, Silva MS, Cunha EVL, Souza MFV, Batista LM, Diniz MFFM 2007. Natural products with antileprotic activity. Rev Bras Farmacogn 17: 141-148.

Barbosa-Filho JM, Alencar AA, Nunes XP, Tomaz ACA, Sena-Filho JG, Athayde-Filho PF, Silva MS, Souza MFV, da-Cunha EVL 2008a. Sources of alpha-, beta, gamma-, delta- and epsilon-carotenes: A twentieth century review. Rev Bras Farmacogn 18: 135-154.

Barbosa-Filho JM, Cunha RM, Dias CS, Athayde-Filho PF, Silva MS, Cunha EVL, Machado MIL, Craveiro AA, Medeiros IA 2008b. GC-MS Analysis and cardiovascular activity of the essential oil of Ocotea duckei. Rev Bras Farmacogn 18: 37-41.

Brandão MGL, Cosenza GP, Moreira RA, Monte-Mor RLM 2006. Medicinal plants and other botanical products from the Brazilian Official Pharmacopoeia. Rev Bras Farmacogn 16: 408-420.

Bruneton J 1991. Elementos de fitoquimica y de farmacognosia. Zaragoza, España: Editorial Acribia, S.A.

Callado CH, Pugialli HRP, Costa CG, Cunha M, Marquete O, Barros CF 1997. Anatomia ecológica e micromorfologia foliar de espécies de floresta montana na reserva ecológica de Macaé de Cima. Pp. 275-296. In: Lima, HC, Guedes-Bruni, RR (ed.). Serra de Macaé de Cima: Diversidade Florística e Conservação em Mata Atlântica. Rio de Janeiro: Jardim Botânico do Rio de Janeiro.

Callado CH, Freitas MHV, Lima HRP, Costa CG 2006. Diferenciação da epiderme múltipla da lâmina foliar de Mollinedia oligantha Perkins. Floresta $e$ Ambiente 12: 75-78.

Carneiro CMTS, Neves LJ, Pereira EFR, Pereira NA 1989. Mecanismo tóxico de comigo-ninguém-pode, Dieffenbachia picta Schott., Araceae. Rev Bras Farm 70: 11-13.

Corrêa MFP, Melo GO, Costa SS 2008. Substâncias de origem vegetal potencialmente úteis na terapia da Asma. Rev Bras Farmacogn 18 (Supl.): 785-797.

Ferreira LS, Marsola FJ, Teixeira SP 2006. Anatomia dos órgãos vegetativos de Dieffenbachia picta Schott
(Araceae) com ênfase na distribuição de cristais, laticíferos e grãos de amido. Rev Bras Farmacogn 16 (Supl.): 664-670.

Fischer DCH, Kato ETM, Oliveira F 1998. Caracterização farmacognóstica de limoeiro-bravo - Siparuna apiosyce (Mart.) A. DC. - Monimiaceae. Lecta.16: 9-28.

Gottlieb OR 1972. Chemosystematics of the Lauraceae. Phytochemistry 11: 1537-1570.

Gottlieb OR, Salatino A 1987. Função e evolução de óleos essenciais e de suas estruturas secretoras. Ciência e Cultura 39: 707-715.

Gundidza M, Chinyanganya F, Chagonda L, De Pooter HL, Mavi S 1994. Phytoconstituents and antimicrobial activity of the leaf essential oil of Clausena anisata (Willd.) J. D. Hook ex. Benth. Flavour Frag $J$ 9: 299-303.

Harborne JB 1991. Recent advances in the ecological chemistry of plant terpenoids. In: Harborne JB, Tomas-barberán FA (ed.). Ecological chemistry and biochemistry of plant terpenoids. Proceedings of the Phytochemical Society of Europe. Vol. 31. Oxford: Claredon Press.

Hokwerda H, Bos R, Tattje DHE, Malingre TM 1982. Composition of essential oils of Laurus nobilis, $L$. nobilis var. angustifolia and Laurus azorica. Planta Med 44: 116-119.

Hickey LJ 1979. A revised classification of the architecture of dicotyledonous leaves. In: Metcalfe, CR, Chalk L. (ed.). Anatomy of the dicotyledons, Vol. I. $2^{\text {nd }}$. ed. Oxford: Claredon Press: 25-39.

Jennet-Siems K, Kraft C, Siems K, Jakupovic J, Solis PN, Gupta MP, Bienzle U 2003. Sipaucins A-C, sesquiterpenoids from Siparuna pauciflora. Phytochemistry 63: 377-381.

Johansen DA 1940. Plant Microtecnique. $1^{\text {st }}$. ed. New York: Mc Graw Hill Company.

Jorge-Neto J, Valentin RL, Mancini B 1989. Análise cromatográfica do óleo essencial do boldo-do-Chile: determinação quantitativa. Rev Cienc Farm 11: 181187.

Leitão GG, Lopes D, Menezes FS, Kaplan MAC, Craveiro AA, Alencar JW 1991. Essential oils from Brazilian Aristolochia. J Essent Oil Res 3: 403-408.

Leitão GG, Simas NK, Soares SSV, Brito APP, Claros BMG, Brito TBM, Monache FD 1999. Chemistry and pharmacology of Monimiaceae: a special focus on Siparuna and Mollinedia. J Ethnopharmacol 65: 87102.

Lorence DH 1985. A monograph of the Monimiaceae (Laurales) in the malgasy region (Southwest indian ocean). Ann Mo Bot Gard 72: 1-165.

Mac Lafferty FW, Stanffer DB 1989. Registry of mass spectral data, Vol. I; II. New York: Wiley-Interscience Publishers.

Marques CA 2007. Aspectos morfo-anatômicos, fitoquímicos e ensaios biológicos em Hennecartia omphalandra J. Poisson (Monimiaceae): uma planta tóxica. Rio de Janeiro, 125p. Tese de doutorado - Programa de Pós Graduação em Biotecnologia Vegetal, UFRJ.

Marques CA, Leitão GG, Bizzo HR, Kranz WM, Peixoto AL, Vieira RC 2008. Considerações anatômicas e análise de óleo essencial do hipanto e do fruto de Hennecartia 
omphalandra J. Poisson (Monimiaceae). Rev Bras Farmacogn 18: 415-429.

Metcalfe CR 1987. Anatomy of the Dicotyledons. Vol. III. $2^{\text {a }}$ ed. Oxford: Oxford Claredon Press.

Milanez FR, Monteiro-Neto H 1956. Origem dos laticíferos do embrião de Euphorbia pulcherrima Willd. Rodriguésia 18/19: 351-424.

Money LL, Bailey IW, Swamy BGL 1950. The morphology and relationships of the Monimiaceae. Journal of the Arnold Arboretum 31: 372-403.

Moreira DL, Simas NK, Leitão GG 2001. Essential oils from four Brazilian Mollinedia. Ver Bras Farm 82: 43-45.

Nimer E 1989. Climatologia do Brasil. Rio de Janeiro: DERNA/IBGE.

Palma S, Luján C, Llabot JM, Barboza G, Manzo RH, Allemandi DA 2002. Design of Peumus boldus tablets by direct compression using a novel dry plant extract. Int J Pharm 233: 191-198.

Panizza S, Scavone O, Rocha AB 1982. Morfodiagnose da maconha (Cannabis sativa L.). Rev Cienc Farm 4: 39-45.

Peixoto AL 1976. Monimiaceae do Brasil. O gênero Hennecartia Poisson. Bradea 2: 71-77.

Peixoto AL 1979. Contribuição ao conhecimento da seção Exappendiculatae Perk. do gênero Mollinedia R. et. P. (Monimiaceae). Rodriguésia 31: 135-222.

Pietta P, Mauri P, Manera E, Ceva P 1988. Determination of isoquinoline alkaloids from Peumus boldus by highperformance liquid chromatography. $J$ Chromatogr A 457: 442-445.

Priestap HA, Baren CM van, Lira PL, Coussio JD, Bandoni AL 2003. Volatile constuents of Aristolochia argentina. Phytochemistry 63: 221-225.

Rao TA, Bhupal OP 1973. Typology of sclereids. Proc Indian Acad Sci 80B: 41-55.

Rizzini CT, Mors W 1976. Botânica Econômica Brasileira. $1^{\text {a }}$ ed. São Paulo: EDUSP.

Ruiz ALTG, Taffarello D, Souza VHS, Carvalho JE 2008. Farmacologia e toxicologia de Peumus boldus e Baccharis genistelloides. Rev Bras Farmacogn 18: 295-300.

Rury PM, Dickson WC 1977. Leaf venation patterns of the genus Hibbertia (Dilleniaceae). Journal of the Arnold Arboretum 58: 209-241.

Ruzin SE 1999. Plant microtechnique and microscopy. New York/ Oxford: Oxford University Press.

Saúde-Guimarães DA, Faria AR 2007. Substâncias da natureza com atividade anti-Trypanosoma cruzi. Rev Bras Farmacogn 17: 455-465.

Schenkel EP, Zannin M, Mentz LA, Bordignon SAL, Irgang B 2002. Plantas tóxicas. Pp. 767- 800. In: Simões CMO et al. (org.) Farmacognosia: da planta ao medicamento. $4^{\mathrm{a}}$ ed. Porto Alegre/ Florianópolis: Ed. Universidade/ UFRGS/ Ed. da UFSC.

Simões CMO, Spitzer V 2002. Óleos voláteis. Pp. 397-425. In: Simões, C.M.O. et al. (org.) Farmacognosia: da planta ao medicamento. $4^{\mathrm{a}}$ ed. Porto Alegre/ Florianópolis: Ed. Universidade/ UFRGS/ Ed. da UFSC.

Solereder H 1908. Systematic anatomy of the dicotyledons. Vol. I e II. Oxford: Claredon Press.

Sousa FCF, Melo CTV, Citó MCO, Félix FHC, Vasconcelos
SMM, Fonteles MMF, Barbosa-Filho JM, Viana GSB 2008. Plantas medicinais e seus constituintes bioativos: Uma revisão da bioatividade e potenciais benefícios nos distúrbios da ansiedade em modelos animais. Rev Bras Farmacogn 18: 642-654.

Vieira PC, Fernandes JB, Andrei CC 2002. Plantas inseticidas. Pp. 751-766. In: Simões CMO et al. (org.). Farmacognosia: da planta ao medicamento. $4^{\text {a }}$ ed. Porto Alegre/Florianópolis: Ed. Universidade/ UFRGS/ Ed. da UFSC.

Wang G, Li X, Huang F, Zhao J, Ding H, Cunningham C, Coad JE, Flynn DC, Reed E, Li QQ 2005. Antitumor effect of beta-elemene in non-small-cell lung cancer cells is mediated via induction of cell cycle arrest and apoptotic cell death. Cell Mol Life Sci 62: 881-893.

Wilkinson HP 1979. The plant Surface (Mainly Leaf). Part I: Stomata. In: Metcalfe CR, Chalk L. Anatomy of the Dicotyledons. Vol. I. $2^{\text {a }}$ ed. Oxford: Oxford Claredon Press: 97-116.

Wu W, Liu K, Tang X 1999. Preliminary study on the antitumor immuno-protective mechanism of beta-elemene. Zhonghua Zhong Liu Za Zhi. 21: 405-408.

Zou L, Liu W, Yu L 2001. Beta-elemene induces apoptosis of K562 leukemia cells. Zhonghua Zhong Liu Za Zhi. 23: 196-198. 